\title{
EXECUÇÃO PENAL E RESSOCIALIZAÇÃO: CONTRADIÇÕES ENTRE REALIDADE E PREVISÃO LEGISLATIVA
}

\section{PENAL EXECUTION AND RESOCIALIZATION: CONTRADICTIONS BETWEEN REALITY AND LEGAL PROVISION}

RESUMO: Este trabalho está inserido na temática da execução penal, abordando mais especificamente a Lei $n^{\circ}$ 7.210, de 11 de julho de 1984, também conhecida como Lei de Execução Penal (LEP) e os seus problemas de efetivação. Desse modo, como objeto de estudo, tem a própria execução penal, a lei que a regulamenta e artigos que versam sobre o tema em questão. A partir do estudo destes objetos, proposita identificar os principais problemas de efetividade da LEP, utilizando-se, para isso, de uma revisão de uma literatura, realizada por meio da pesquisa no Portal de Periódicos CAPES e na base de dados da SciELO. Os resultados obtidos revelam que as principais críticas referentes aos problemas de efetividade da LEP giram em torno de questões relativas à inércia dos poderes Executivo e Legislativo; às péssimas condições estruturais dos estabelecimentos prisionais brasileiros; às afrontas ao princípio da individualização da pena, em seus mais variados horizontes de aplicação e também, segundo parte dos autores, às contradições que são indissociáveis do sistema penal retributivo e encarcerador adotado no Brasil e na maior parte do mudo. Percebeu-se, entretanto, que as críticas referentes aos problemas de efetivação da LEP não se concentraram em um fator em particular: a maior parte dos autores faz comentários gerais em relação a estas questões, sem se debruçar em uma única realidade concreta. Concluiu-se que há necessidade de que sejam realizados estudos mais aprofundados neste sentido, de modo a construir conhecimentos específicos quanto aos direitos e assistências previstas ao preso. A realização de tais pesquisas possibilitará o desempenho da função da execução penal, nos termos da legislação vigente.

Palavras-chave: Execução Penal. Ressocialização. Reincidência.

ABSTRACT: This study is established to the criminal execution area, approaching more specifically the Law No. 7,210, of July 11, 1984, also known as Criminal Execution Act (CEA) and it's enforcement problems. Therefore, as an object of study, it has the criminal execution, the Act that regulates it and articles that deal with the subject in question. Based on the study of these objects, it is proposed to identify the CEA's main effectiveness issues and using, for this, a literature review, carried out through research in the CAPES Journal Portal and in the SciELO database. The results obtained reveals that the main criticisms regarding the problems of effectiveness of the CEA revolve around issues related to the inertia of the Executive and 
Legislative powers; the terrible structural conditions of brazilian prisons; the disrespect to the principle of individualization of punishment, in its most varied horizons of application and also, according to part of the authors, to the contradictions that are inseparable from the retributive and incarcerative penal systems adopted in Brazil and in most of the world. It was noticed, however, that the criticisms regarding the execution of the CEA did not focus on one specific factor: most authors make general comments about these issues, not focusing on the actual reality. It was concluded that there is a need for more in-depth studies in this sense, in order to build specific knowledge regarding the rights and assistance provided to the prisoner. The realization of such researches will enable the implementation of the CEA, under the terms of the current legislation.

Keywords: Criminal Execution. Resocialization. Recidivism.

\section{INTRODUÇÃO}

Debater a execução penal é sempre importante, tendo em vista que, a depender de como este debate se realiza, se manifestarão de forma positiva ou negativa os frutos da prisão na sociedade. Todavia, no quarto país que mais encarcera no mundo, segundo dados do Ministério da Justiça ${ }^{1}$, a tarefa de estudar tal tema não somente é importante, mas extremamente necessária e urgente. É preciso conhecer a realidade em que vivem os cerca de 600 mil brasileiros que se encontram privados de liberdade nas mais de mil unidades prisionais do país ${ }^{2}$ e lutar pela garantia de seu mínimo existencial.

No Brasil, que se afirma como um Estado Democrático de Direito, esta pauta - da garantia dos direitos da população carcerária -, se justifica por si só. Ainda assim, o tema é legitimado a partir de argumentos subsidiários. Entende-se, nesse sentido, que o tratamento desumano dado aos presos não afeta somente a estes, mas a toda a sociedade, pois se converte, posteriormente, no aumento dos índices de violência e criminalidade, além de evidenciar um Estado de exceção, cuja regra de Direito é violada sistematicamente, com anuência do Poder Público e da sociedade. O indivíduo que se encontra privado de liberdade, a partir da progressão de regime ou do cumprimento de pena, retornará ao convívio social, sendo benéfico a todos que este mesmo indivíduo tenha recebido em cárcere um tratamento que possibilite a sua reintegração.

${ }^{1}$ Em junho de 2014, o Departamento Penitenciário Nacional (Depen), vinculado ao Ministério da Justiça, por meio do Levantamento Nacional De Informações Penitenciárias - INFOPEN, divulgou a informação de que o Brasil possui uma população prisional de 607.731 presos. Neste sentido: "Em números absolutos, o Brasil tem a quarta maior população prisional, ficando atrás apenas dos Estados Unidos, da China e da Rússia. Cotejada a taxa de aprisionamento desses países, constata-se que, em termos relativos, a população prisional brasileira também é a quarta maior: somente os Estados Unidos, a Rússia e a Tailândia têm um contingente prisional mais elevado.” (BRASIL, 2014, p. 11).

${ }^{2}$ Ainda de acordo com o Levantamento Nacional De Informações Penitenciárias - INFOPEN, publicado em junho de 2014 : "No Brasil, existem, ao todo, 1.424 unidades prisionais. Quatro desses estabelecimentos são penitenciárias federais, as demais unidades são estabelecimentos estaduais.” (BRASIL, 2014, p. 23). 
É nesse contexto que se insere a discussão a respeito da Lei de Execução Penal (LEP), que prevê aos apenados um amplo rol de garantias e assistências. Estas garantias, contudo, não se concretizaram, dando lugar a uma série de violações que tornam a prisão um ambiente degradante que fortalece a formação de indivíduos antissociais e tendentes a reincidir no crime.

Em face dessa problemática, surgem os seguintes questionamentos: o que diz a Lei de Execução Penal em relação às condições em que devem se encontrar o ambiente do cárcere? Como conceituar ressocialização e reincidência, fenômenos intrinsecamente relacionados à discussão sobre execução penal? Quais são as principais críticas existentes em relação à efetividade dos dispositivos da LEP?

As perguntas supracitadas são complexas e não possuem uma única resposta. O presente artigo, por seu turno, se propõe a respondê-las a partir da análise à legislação e aos discursos dos pesquisadores brasileiros da área de execução penal e segurança pública, captados por meio de uma revisão de literatura sobre o tema.

Desse modo, em busca de compreender de maneira satisfatória a contradição existente entre a previsão legislativa e a realidade apontada a partir do ponto de vista da academia, será realizada, inicialmente, uma breve contextualização a respeito da Lei de Execução Penal; em seguida, serão feitas algumas delimitações metodológicas, com o objetivo de esclarecer como foi realizada a revisão de literatura e de compartilhar os principais conceitos de ressocialização e reincidência utilizados na abordagem do tema. Finalmente, serão analisados os resultados da mencionada revisão, ou seja, serão apresentados os fatores apontados pelos pesquisadores como responsáveis pela ausência de efetividade das previsões da LEP.

\section{LEI DE EXECUÇÃO PENAL: BREVEAPRESENTAÇÃO}

De forma complementar ao Código de Processo Penal, destaca-se, na legislação referente à execução das penas, a Lei no 7.210, de 11 de julho de 1984, mais conhecida como Lei de Execução Penal. A referida lei representou um grande avanço no que tange à efetivação dos direitos da população carcerária, pois possui um caráter preponderantemente garantista, reafirmando vários dos princípios e direitos fundamentais positivados no artigo $5^{\circ}$ da Constituição Federal. Em suma, a LEP prevê aos apenados o suporte e o amparo do Estado em relação às suas necessidades básicas, buscando assegurar, assim, todos os direitos não atingidos pela sentença condenatória ou pela lei, conforme determina o seu artigo $3^{0^{3}}$.

Este capítulo buscará, de forma breve, versar sobre os objetivos da execução penal e também sobre as assistências - materiais, à saúde, jurídica, educacional, social e religiosa - prestadas ao preso, fornecendo, desse modo, o aporte necessário à melhor compreensão das críticas feitas à legislação em questão, que serão posteriormente apresentadas.

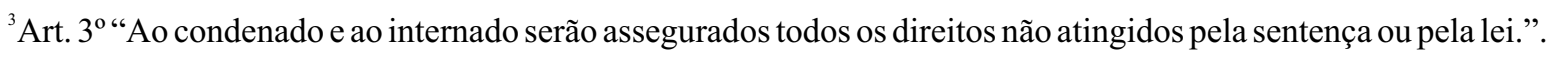




\subsection{Os objetivos da execução penal}

Segundo a LEP, a execução penal possui a dupla função de, por um lado, punir, fazendo com que o indivíduo perceba o caráter de reprovação social da conduta praticada por ele e, por outro lado, reintegrar o apenado à sociedade, proporcionando a este um ambiente propício à sociabilidade. Neste sentido está redigido o seu artigo $1^{\circ}$, que diz: “A execução penal tem por objetivo efetivar as disposições de sentença ou decisão criminal e proporcionar condições para a harmônica integração social do condenado e do internado." (sem itálico no original).

O caráter preponderantemente retributivo da execução está presente na primeira parte do enunciado legal supracitado, que apresenta a efetivação dos dispositivos da sentença ou decisão criminal como um dos seus objetivos. Observa-se, aqui, a função de prevenção especial negativa, que se efetiva por meio da segregação momentânea do indivíduo em relação à sociedade (GRECO, 2017, p. 62).

Esta função meramente punitiva e de prevenção negativa, entretanto, não compreende a totalidade dos objetivos da execução penal, pois, como segundo objetivo citado pela lei, tem-se a integração social do indivíduo. Percebe-se, neste momento, a ideia de prevenção especial positiva, pela qual à pena é atribuída a função de fazer com que o sentenciado desista de prosseguir na trajetória delitiva.

Percebe-se, pela função de reintegrar socialmente o apenado, prevista no artigo $1^{\circ}$ da LEP, que o discurso meramente punitivista ligado às teorias absolutas da pena não encontra amparo na legislação. Desse modo, todo o tratamento desumano ou que visa à punição pela punição está baseado na ilegalidade e, em alguns casos, até mesmo na inconstitucionalidade, como bem reconheceu o Supremo Tribunal Federal em 2015, quando julgou medida cautelar na Arguição de Descumprimento de Preceito Fundamental n 347/DF, em decisão que deu ao sistema penitenciário nacional o status de estado de coisas inconstitucional.

Conforme observa Sequeira (2006, p. 668): "Na realidade, apesar do discurso ideológico da Lei de Execuções Penais, estamos sob uma lógica penal vingativa, com o objetivo de destruir esse outro à margem da sociedade; portanto, o que predomina é o caráter ilegal da prisão". Compreende-se, portanto, que esta situação de ilegalidade e inconstitucionalidade se manifesta de forma perene no sistema penitenciário brasileiro.

\subsection{As assistências prestadas ao preso}

Diz o caput do artigo 10 da LEP que a "assistência ao preso e ao internado é dever do Estado, objetivando prevenir o crime e orientar o retorno à convivência em sociedade". O legislador, visando possibilitar o cumprimento do papel reintegrador da pena, estabeleceu, no capítulo II da referida lei, as várias assistências que devem ser prestadas pelo Estado ao preso, sendo elas: assistência material, à saúde, jurídica, educacional, social e religiosa.

Em relação à assistência material, entende-se que esta visa garantir aos presos a satisfação de suas 
necessidades materiais mais básicas. Compreende, assim, a garantia de alimentação, vestuário e instalações higiênicas (art. 12), além da disposição de espaços de venda de produtos e objetos não fornecidos e permitidos pela Administração (art. 13).

A assistência à saúde, por sua vez, possui caráter preventivo e curativo, e abarca o atendimento médico, farmacêutico e odontológico (art. 14). Prevê o parágrafo $2^{\circ}$ do artigo 14 que o atendimento ao preso poderá ser realizado em ambiente externo ao do estabelecimento penal, quando este não possuir a estrutura adequada para fornecê-lo. Além disso, tal assistência compreende também o acompanhamento médico à mulher, “principalmente no pré-natal e no pós-parto, extensivo ao recém-nascido.” (art. 14, § 3o).

A assistência jurídica, regulamentada nos artigos 15 e 16 da LEP, está relacionada ao direito que o preso hipossuficiente possui de ser assistido por um defensor público, de maneira integral e gratuita, além do direito que este possui de ter acesso ao seu processo criminal, dentro do estabelecimento penal.

No concernente à assistência educacional, ressalta-se que esta abrange o direito à formação escolar e também à profissionalização, visando possibilitar ao apenado a capacitação para que este adquira as condições de obter meios lícitos de subsistência. Desse modo, dispõe o artigo 18 que o ensino de $1^{\circ}$ grau é obrigatório, e que o ensino médio, regular ou supletivo, deve ser implantado nos presídios, "em obediência ao preceito constitucional de sua universalização”. Em relação ao ensino profissional, afirma o artigo 19 que este deve ser ministrado não somente no nível de iniciação, mas também no de aperfeiçoamento técnico.

No que tange à assistência social, determina o artigo 22 da LEP que esta "tem por finalidade amparar o preso e o internado e prepará-los para o retorno à liberdade”. Destarte, são atribuídas ao serviço social, no artigo 23, uma série de tarefas, que compreendem a promoção de recreação nos estabelecimentos prisionais, 0 auxílio na obtenção de documentos, a orientação e amparo às famílias dos presos, entre outros.

A assistência religiosa, por fim, está prevista no artigo 24, que prescreve que o estabelecimento prisional deve possuir um ambiente adequado para a realização de cultos religiosos, que os presos têm o direito - e não a obrigação - a participar dos eventos religiosos organizados no estabelecimento prisional e também a possuir livros de instrução religiosa. É importante salientar que, tendo em vista a laicidade do Estado brasileiro, é respeitada a liberdade de culto, de modo que o apenado não poderá sofrer qualquer tipo de discriminação em virtude da religião que escolha professar.

Também se faz importante mencionar que o rol de garantias mencionado, ainda que extenso, é exemplificativo, de modo que nada obsta que, além das assistências previstas de forma expressa em lei, sejam prestados ao preso outros tipos de auxílio - sem que, obviamente, se deturpe o sentido da pena de privação de liberdade prevista na sentença condenatória.

Pode-se concluir, dessa forma, que o Brasil possui um cenário legislativo favorável à reintegração social do apenado, pois prevê diversas assistências e garantias que visam instrumentalizar a sua reintegração no seio da sociedade. Este cenário, entretanto, destoa da realidade fática observada no país, de modo que a lei encontra sérias dificuldades para se concretizar em proteção efetiva aos direitos da população carcerária. Conforme afirmou o ministro Marco Aurélio: 
Apesar de muitos dos direitos violados serem assegurados na Lei $\mathrm{n}^{\mathrm{0}} 7.210 / 84-$ Lei de Execução Penal - e na Lei Complementar no 79/94 - Lei do Fundo Penitenciário Nacional -, assiste-se à omissão reiterada e persistente das autoridades públicas no cumprimento das obrigações estabelecidas em favor dos presos. Verifica-se situação de fracasso das políticas legislativas, administrativas e orçamentárias. Há defeito generalizado e estrutural de políticas públicas e nada é feito pelos Poderes Executivo e Legislativo para transformar o quadro. (ADPF n ${ }^{\circ} 347 / \mathrm{DF}, 2015$, p. 27).

Resta investigar, portanto, quais situações impedem que as assistências mencionadas se tornem uma realidade nos estabelecimentos prisionais do país e, consequentemente, que a Lei de Execução Penal tenha sua aplicação garantida.

\section{REVISÃO DE LITERATURAA RESPEITO DA RESSOCIALIZAÇÃO E REINCIDÊNCIA}

Como já mencionado, com o objetivo de responder aos questionamentos que motivaram a presente pesquisa, foi utilizada, como instrumento metodológico, uma revisão de literatura acerca do tema. Para realizá-la, foram consultadas as bases de dados da Scientific Electronic Library Online (SciELO) e o Portal de Periódicos da Coordenação de Aperfeiçoamento de Pessoal de Nível Superior (CAPES), a partir das quais se pôde obter artigos brasileiros publicados entre o período de 2000 a 2018. Tal pesquisa teve como descritores os termos "reincidência" e/ou "ressocialização", sendo estes escolhidos em virtude da sua abrangência e do fato de estarem intrinsecamente ligados ao tema de execução penal - a ressocialização é um dos objetivos da LEP, que a menciona utilizando o termo "integração social", e a reincidência, por sua vez, é uma consequência da não efetivação dos dispositivos desta mesma lei.

Diante dos trabalhos encontrados, foi feita uma leitura de seus títulos e resumos, de modo a selecionar apenas o material que se encaixava nos critérios adotados nesta pesquisa. Desse modo, foram selecionados os artigos que: 1) tratam sobre o tema da reincidência criminal ou da ressocialização de apenados e/ou socioeducandos; 2) foram publicados entre o período de 2000 a 2018; e que 3) estão redigidos em língua portuguesa. Os artigos selecionados estão dispostos nas figuras abaixo:

Figura 1-Artigos obtidos a partir da pesquisa na plataforma SciELO.
\begin{tabular}{|l|c|c|}
\hline \multicolumn{1}{|c|}{ Título do trabalho } & $\begin{array}{c}\text { Ano de } \\
\text { publicação }\end{array}$ & Autor/autores \\
\hline $\begin{array}{l}\text { Significados da ressocialização para } \\
\text { agentes penitenciárias em uma prisão } \\
\text { feminina: entre o cuidado e controle. }\end{array}$ & 2017 & $\begin{array}{c}\text { BARCINSKI, Mariana; CUNICO, Sabrina } \\
\text { Daiana; BRASIL, Mariana Valentim. }\end{array}$ \\
\hline $\begin{array}{l}\text { Fatores sociais determinantes da } \\
\text { reincidência criminal no brasil: o caso } \\
\text { de Minas Gerais. }\end{array}$ & 2017 & $\begin{array}{l}\text { SAPORI, Luis Flávio; SANTOS, Roberta } \\
\text { Fernandes; MAAS, Lucas Wan Der. }\end{array}$ \\
\hline $\begin{array}{l}\text { Disciplina ou ressocialização? } \\
\text { Racionalidades punitivas, trabalho } \\
\text { prisional e politica penitenciária. }\end{array}$ & 2015 & MACHADO, Bruno Amaral; SLONIAK, \\
\hline $\begin{array}{l}\text { Crime-prisão-liberdade-crime: } \\
\text { círculo perverso da reincidência no } \\
\text { crime. }\end{array}$ & 2011 & FERREIRA, Angelita Rangel. \\
\hline $\begin{array}{l}\text { Ressocialização: o desafio da educação } \\
\text { no sistema prisional feminino }\end{array}$ & 2010 & CUNHA, Elizângela Lelis. \\
\hline $\begin{array}{l}\text { Análise comparativa dos efeitos da } \\
\text { base socioeconômica, dos tipos de } \\
\text { crime e das condições de prisão na } \\
\text { reincidência criminal. }\end{array}$ & 2002 & MARIÑo, Juan Mario Fandino. \\
\hline
\end{tabular}

Fonte: elaborada pela autora. 
Figura 2 - Artigos obtidos a partir da pesquisa no Portal de Periódicos CAPES.

\begin{tabular}{|c|c|c|}
\hline Titulo do trabalho & $\begin{array}{c}\text { Ano de } \\
\text { publicação }\end{array}$ & Autor/autores \\
\hline Reincidència ou repescagem? & 2007 & FAJARDO, Sinara \\
\hline $\begin{array}{l}\text { Lei de Execução Penal (LEP) em } \\
\text { penitenciária de segurança máxima } \\
\text { para ressocialização de apenados: } \\
\text { análise de politicas públicas. }\end{array}$ & 2017 & $\begin{array}{l}\text { SOARES, Agnaldo Moreira; PEREIRA, } \\
\text { Geovana Rodrigues; PEREIRA, Suely } \\
\text { Rodrigues; FREITAS, Ronilson Ferreira. }\end{array}$ \\
\hline $\begin{array}{l}\text { Contextos de ressocialização do } \\
\text { privado de liberdade no atual sistema } \\
\text { prisional brasileiro. }\end{array}$ & 2017 & $\begin{array}{l}\text { FONSECA, Carlos Eduardo Prates; } \\
\text { RODRIGUES, Jéssica Marques. }\end{array}$ \\
\hline $\begin{array}{l}\text { Fatores sociais determinantes da } \\
\text { reincidência criminal no brasil: o caso } \\
\text { de Minas Gerais. }\end{array}$ & 2017 & $\begin{array}{l}\text { SAPORI, Luis Flávio; SANTOS, Roberta } \\
\text { Fernandes; MAAS, Lucas Wan Der. }\end{array}$ \\
\hline $\begin{array}{l}\text { Reincidència criminal e penitenciária: } \\
\text { aspectos conceituais, metodológicos, } \\
\text { políticos e ideológicos. }\end{array}$ & 2016 & JULIÃO; Elionaldo Fernandes. \\
\hline $\begin{array}{l}\text { Os desafios da prática socioeducativa } \\
\text { de previsão de liberdade em } \\
\text { adolescentes em conflito com a lei: } \\
\text { ressocialização ou exclusão social? }\end{array}$ & 2009 & $\begin{array}{l}\text { ESTEVAM, Ionara Dantas; } \\
\text { COUTINHO, Maria da Penha de Lima; } \\
\text { ARAÚJO, Ludgleydson Fernandes de. }\end{array}$ \\
\hline
\end{tabular}

Fonte: elaborada pela autora.

Foram obtidos, portanto, 11 artigos - seis pela CAPES e seis pela SciELO, de modo que um destes 11 foi contado somente uma vez, pois presente em ambas bases de dados -, escritos por graduandos, mestres e doutores da área. Tais artigos compreendem áreas de conhecimento diversas (como Direito Penal, Psicologia, Serviço Social, Sociologia, entre outras). A partir desse material, foi feita uma análise qualitativa, de modo a compreender como essas publicações conceituam e enxergam o tema da reincidência e da ressocialização, e também qual o tipo de abordagem é mais realizado no estudo desses temas.

Ressalta-se, desde já, que ressocialização e reincidência são termos extremamente polissêmicos, de modo que, ao definir estes fenômenos, cada autor consultado na revisão de literatura salientou uma particularidade distinta, ou, ainda, um critério distinto a ser observado na conceituação desses vocábulos.

\subsection{Principais considerações a respeito da ressocialização}

Em relação à ressocialização, percebe-se que a maior parte dos autores não a conceitua de forma expressa, de modo que é possível abstrair de forma apenas implícita que estes a compreendem como o fenômeno observado quando o indivíduo, tendo cumprido sua pena, abandona a trajetória delitiva, mostrando-se apto à convivência social.

Barcinski, Cúnico e Brasil (2017) ressaltam que há um problema na forma pela qual se debate a ressocialização no Brasil, tendo em vista que esta é encarada como uma responsabilidade exclusiva do preso e dos profissionais do sistema de segurança pública. As autoras, além disso, compreendem os fenômenos da ressocialização e da reincidência como duas faces de uma mesma moeda. Neste sentido, afirmam:

[...] a individualização do processo que convencionamos chamar de ressocialização dos presos é personificada em indivíduos específicos, deixando intocado o caráter social do processo e das suas possibilidades de êxito. São os presos e os profissionais do sistema que constroem juntos planos individuais visando à reinserção social dos egressos do sistema prisional. Desta forma, a consecução satisfatória destes planos, expressa na 
não reincidência, depende da força de vontade e do desejo de mudança do preso, bem como na capacidade técnica dos profissionais do sistema (BARCINSKI et. al. 2017, p. 1261). (grifou-se em itálico)

Concluem, assim, que o processo de ressocialização não deve ser visto como uma responsabilidade única do apenado. Questionam, também, o próprio termo "ressocialização", trazendo a noção de que o termo “reintegração social” pode ser mais adequado:

Portanto, o processo de ressocialização não deve enfocar exclusivamente a pessoa do apenado, mas sim a relação que este estabelece com a sociedade, para que possamos compreender sua conduta desviante e criminosa. Neste sentido, Sá (2000, p. 21) sugere que o termo "reintegração social" seria mais adequado, por reconhecer que o apenado provém de um contexto de marginalização e que o encarceramento representa a oficialização da relação antagônica e excludente estabelecida entre este indivíduo e a esfera social. (BARCINSKI et. al. 2017; p. 1261)

Na verdade, é possível afirmar que a expressão "integração social”, utilizada pelo legislador, no artigo $1^{\circ}$ da LEP, ao definir os objetivos da execução penal, se apresenta como a mais pertinente para fazer referência ao fenômeno em questão, no contexto brasileiro. Não é possível reintegrar quem sempre esteve à margem da sociedade e por isso nunca foi, primeiramente, integrado. Desse modo, o uso do termo sem o prefixo "re" é adequado para descrever a realidade da maior parte dos apenados do país, que sempre fizeram parte dos grupos sociais mais excluídos. Malgrado tais discussões, extremamente válidas, o termo ressocialização continuará a ser utilizado neste trabalho como um sinônimo de integração/reintegração social, por questões meramente didáticas.

Desse modo, voltando às problematizações trazidas por Barcinski et. al., conclui-se que a ressocialização do apenado deve ser vista como um objetivo a ser perseguido por todos os setores da sociedade, e não como uma iniciativa unilateral dos sujeitos desta narrativa. As autoras não foram as únicas a enfatizar esta questão. Neste sentido, também se manifestaram Soares et. al. (2017, p. 60):

A ressocialização compreende um amplo trabalho no campo psicossocial do delinquente, assim como da sociedade que será o órgão acolhedor desse indivíduo quando efetivar o cumprimento da pena, proporcionando condições para que o mesmo não volte a reincidir.

Concentrando-se em outra faceta do mesmo fenômeno, alguns pesquisadores chamam atenção para o fato de que o conceito de ressocialização está intimamente ligado à ideia de educação e capacitação profissional e, portanto, à garantia da assistência educacional prevista na seção V da LEP ${ }^{4}$. Desse modo, apontam como indispensável para que haja reinserção social a existência de políticas de qualificação e de trabalho no cárcere, tendo em vista que é somente a partir da capacitação obtida que muitos poderão

\footnotetext{
${ }^{4}$ (MACHADO; SLONIAK, 2015); (CUNHA, 2010); (FONSECA; RODRIGUES, 2017).
} 
obter uma fonte lícita de renda:

Nesse sentido, Oliveira (2012) defende que o trabalho e a educação são os melhores meios para propiciar a recuperação do condenado, podendo ser considerados como "passaportes" para a sua reinserção social. Isto porque o trabalho e a educação podem recuperar a autoestima do detento, além de promover sua autossuficiência, favorecendo a sua capacitação e consequentemente desenvolvendo a sua independência na vida em sociedade. (FONSECA; RODRIGUES, 2017, p. 37)

Outras pesquisas abordaram o tema utilizando a metodologia da teoria das representações sociais ${ }^{5}$. Utilizando esta técnica, Estevam, Coutinho e Araújo (2009) abordam a questão da ressocialização a partir de um enfoque pouco convencional, mas não menos interessante: os sentimentos negativos que os adolescentes que cumprem medida socioeducativa de internação possuem em relação à prática socioeducativa de privação de liberdade, demonstrando que, na visão dos adolescentes, esta é hostil e desfavorável à sua reintegração social.

Machado e Sloniak (2015), por sua vez, escolheram analisar as representações sociais de atores diretamente envolvidos na implantação e execução da política penitenciária-juízes de direito, promotores de justiça, gestores e executores do Distrito Federal -, chegando à conclusão que estes profissionais veem no descaso dos poderes Executivo e Legislativo para com a segurança pública um dos principais fatores pelos quais a ressocialização dos apenados não é uma realidade.

\subsection{O fenômeno da reincidência a partir da perspectiva dos pesquisadores}

Em relação à reincidência, também são vãs as tentativas de sistematizar a literatura de forma a captar um conceito universal deste fenômeno. Cada autor, em cada pesquisa, utiliza critérios metodológicos diferentes, de modo que não é possível falar na reincidência (singular), mas nas reincidências (plural), especificando, sempre, qual o conceito adotado em cada contexto.

Alguns pesquisadores ${ }^{6}$, em seus artigos, optaram por mencionar a definição legislativa de reincidência, presente no Código Penal brasileiro, que no artigo 63, preceitua: "verifica-se a reincidência quando o agente comete novo crime, depois de transitar em julgado a sentença que, no País ou no estrangeiro, o tenha condenado por crime anterior".

Em relação às formas pelas quais os pesquisadores das ciências sociais compreendem e conceituam a reincidência, Elionaldo Fernandes Julião (2016) realizou pesquisa bastante elucidativa. Neste sentido, preleciona:

No campo das ciências sociais, em que é comum explicitar o movimento geral da criminalidade a partir do exame de seus fundamentos histórico-estruturais, o conceito reincidência apresenta diversas e variadas implicações que vão desde a natureza 
etimológica do vocábulo, à metodologia empregada para a sua mensuração, até mesmo da interpretação das suas variáveis. Em alguns estudos sociológicos, principalmente versando sobre o sistema penitenciário, poucos autores arriscaram a definir operativamente o conceito reincidência (criminal e penitenciária). Em linhas gerais, costumam considerar a reincidência a partir de dois aspectos: (1) que o indivíduo foi condenado anteriormente por crime ou contravenção penal, com sentença transitada em julgado, não importando a natureza da pena; e (2) somente a prática de um novo crime ou contravenção penal transitado em julgado e sentenciado/condenado, dentro do prazo contado a partir da data de cumprimento ou extinção da pena (no caso brasileiro, de 5 anos). (JULIÃO, 2016, p. 272)

Como enfatizou o pesquisador, o prazo utilizado juridicamente no Brasil para a averiguação de reincidência é de cinco anos, conforme preceitua o artigo 64, I do Código Penal ${ }^{7}$. Utilizando este lapso temporal, contado a partir do trânsito em julgado da sentença, como parâmetro para enquadrar determinado indivíduo como reincidente, o ordenamento jurídico brasileiro confere a este uma série de consequências negativas no processo penal, como, por exemplo, a consideração da reincidência como fator agravante da pena ${ }^{8}$.

As pesquisas acadêmicas realizadas no país, entretanto, "não se pautaram necessariamente por tal conceituação jurídica. A despeito de rarefeitos, esses estudos privilegiaram o cálculo da reincidência na dimensão penitenciária" (SAPORI et. al. 2017, p. 3). Não faz parte do objetivo do presente artigo analisar minuciosamente as diferentes taxas de reincidência fornecidas pelos cientistas brasileiros em suas pesquisas. Cabe apenas fazer a ressalva de que alguns trabalhos utilizaram a informação divulgada no relatório final da Comissão Parlamentar de Inquérito (CPI), segundo a qual a taxa de reincidência no Brasil oscila entre 70 a $85 \%$ (2009, p. 280), tendo como base dados fornecidos pelo DEPEN. Estes dados, entretanto, diferem do estudo realizado pelo Instituto de Pesquisa Econômica Aplicada (IPEA), que, em 2015, a partir da análise de 817 casos em cinco estados, apresentou estudo concluindo que a taxa de reincidência criminal brasileira corresponde a $24,4 \%$ (2015, p. 23), percentual este bem mais modesto que o anteriormente citado ${ }^{9}$.

Como já se ressaltou, portanto, as taxas de reincidência variam a depender da metodologia utilizada em cada pesquisa, de modo que qualquer tipo de comparação entre esses índices deve ser feita com cautela-é preciso, se realmente se deseja realiza-la, atentar-se aos critérios utilizados em cada pesquisa, de modo a conferir se estes foram, ao menos, similares ou se utilizaram, no mínimo, o mesmo conceito de reincidência.

\footnotetext{
${ }^{7}$ Código Penal, art. 64 - Para efeito de reincidência:

I - não prevalece a condenação anterior, se entre a data do cumprimento ou extinção da pena e a infração posterior tiver decorrido período de tempo superior a 5 (cinco) anos, computado o período de prova da suspensão ou do livramento condicional, se não ocorrer revogação;

${ }^{8}$ Código penal, art. 61. São circunstâncias que sempre agravam a pena, quando não constituem ou qualificam o crime: I - a reincidência; $[\ldots]$.

${ }^{9}$ Estas não foram obviamente, as únicas pesquisas realizadas no Brasil em relação à taxa de reincidência. Na análise do tema, se destacam os estudos de Adorno e Bordini, realizados em 1980 e 1994, que encontraram, respectivamente, taxas de reincidência relativas ao estado de São Paulo correspondentes à 46,03\% e 29,34\%, respectivamente - os resultados são distintos em virtude, principalmente, da metodologia utilizada em cada estudo. Além disso, também se sobressai a pesquisa realizada por Julita Lemgruber (1989), em relação ao estado do Rio de Janeiro, segundo a qual a taxa de reincidência consistia em 30,7\%. Destarte, também se faz importante salientar a pesquisa realizada por Sapori, Santos e Maas (2017), no estado de Minas Gerais, que obteve uma taxa de reincidência criminal em Minas Gerais correspondente a 51,4\% (2017, p. 8).
} 
Outro fator que merece atenção no debate a respeito da reincidência no Brasil é a dificuldade, mencionada por Julião (2016, p. 270), de organização por parte dos gestores do sistema penitenciário do país, tendo em vista a inexistência de um sistema nacional integrado com os dados dos presos brasileiros, o que dificulta as pesquisas e o próprio conhecimento dos governantes quanto à realidade do sistema carcerário.

Além disso, é válido mencionar que a grande parte dos autores consultados na revisão de literatura ${ }^{10}$ menciona fatores sociais, como a pobreza e a estigmatização do preso, como responsáveis pelos altos índices de reincidência criminal. Mariño (2002) a relaciona à questão dos direitos básicos que não são garantidos à parte da população. O consumismo também é um fator mencionado pelo pesquisador. Pela sua perspectiva, a situação de anomia econômica, que significa a "incapacidade de atingir os níveis de vida culturalmente estabelecidos e esperados em função da inexistência dos meios necessários” (MARIÑO, 2002, p. 240), no Brasil, parece estar mais relacionada à reincidência do que a pobreza extrema propriamente dita.

A criminalização de pobreza é apresentada como um dos fatores que impossibilitam, aos mais necessitados, a ampla defesa, tendo em vista que "somente aquele que não possui conhecimento e recursos materiais para se defender é que acaba penalizado, muitas vezes com sentenças e julgamentos tardios e medidas punitivas severas à natureza do delito." (CUNHA, 2010, p. 19). Desse modo, a garantia dos direitos sociais é fator imprescindível para que se rompa o histórico de injustiças realizadas contra a população pobre. Ferreira (2011) partilha de uma perspectiva semelhante, e defende que a única forma de romper com o círculo vicioso da reincidência criminal consiste na garantia, pelo Estado, dos direitos sociais daqueles que vivem em situação de vulnerabilidade.

Em relação à estigmatização do preso e do egresso, Fonseca e Rodrigues (2017) ressaltam que o preconceito da sociedade em relação àqueles que já passaram pelos estabelecimentos prisionais dificulta severamente o plano ressocializador arquitetado pelo legislador brasileiro. Nessa acepção, afirmam:

\begin{abstract}
Sobre a educação e o trabalho, pode-se dizer que, embora em teoria sejam as medidas ressocializadoras mais indicadas e eficazes, na prática, tais medidas podem se mostrar pouco eficientes em alguns casos. Isto porque, apesar de toda a instrução e capacitação oferecida aos presidiários, há outros problemas com os quais eles se deparam ao tentar buscar se adaptar novamente à sociedade. Um destes problemas, por exemplo, pode ser o preconceito encontrado no mercado de trabalho pela sua antiga condição de presidiário, uma vez que este tema ainda é considerado um tabu na sociedade brasileira. (FONSECA; RODRIGUES; 2017,p. 38)
\end{abstract}

Para que as políticas de reinserção social possam avançar, portanto, existem fatores que não se relacionam à questão jurídica ou do jogo político, mas à própria mentalidade da sociedade, que precisa ser reformulada, tendo em vista que, nas palavras de Sapori et. al. (2017, p. 16), "não há como negar que a rejeição de familiares, amigos, vizinhos e das empresas de modo geral afetam diretamente as oportunidades de reinserção social do egresso do sistema prisional”. 


\title{
4 AS PRINCIPAIS FRAGILIDADES NO QUE TANGE À EFETIVAÇÃO DOS DISPOSITIVOS DA LEI DE EXECUÇÃO PENAL
}

Finalmente, no que diz respeito às fragilidades encontradas pelos pesquisadores brasileiros em relação à efetivação dos dispositivos da Lei de Execução Penal, foi percebido, a partir de revisão de literatura, que estas são múltiplas e possuem naturezas completamente diversas. Não há, portanto, somente um entrave específico em relação a esta questão, mas um conjunto de situações que, concomitantemente, se apresentam como prejudiciais à consolidação do plano ressocializador positivado em lei.

Em vista disso, além do que será mencionado de forma secundária e implícita, serão feitos comentários em relação os seguintes pontos, apresentados pela literatura como responsáveis pela ausência de efetividade dos dispositivos da LEP: 1) a questão política, que envolve a falta de apoio popular que o tema da garantia aos direitos das populações carcerárias enfrenta no Brasil; 2) os problemas de infraestrutura dos estabelecimentos prisionais brasileiros e a consequente fragilidade da assistência à saúde; 3) a ausência de individualização da pena, característica de todas as fases da execução penal; e 4) a contradição intrínseca ao modelo punitivo contemporâneo, pela qual se espera que o indivíduo aprenda a conviver em sociedade a partir de uma experiência de privação de liberdade.

\subsection{Aquestão política}

Em relação à questão política, Machado e Sloniak (2015), discorrendo sobre a assistência educacional, mais especificamente sobre a capacitação profissional dos apenados, afirmam que, na concepção dos juízes de direito, promotores de justiça, gestores e executores do Distrito Federal, o principal entrave à efetivação de uma política eficaz de profissionalização dos apenados consiste na ausência de investimentos por parte dos poderes Executivo e Legislativo neste setor. A falta de investimentos, por conseguinte, ocorre porque os governantes não veem o incentivo à ressocialização dos presos como politicamente vantajoso. Nesse sentido:

\begin{abstract}
A população carcerária seria vista pela sociedade, e não apenas pela classe política, como "escória", indigna da utilização de recursos públicos. Estes deveriam ser realocados para áreas de interesse social, rol no qual não se contemplaria o investimento em melhoria de condições das prisões ou adequação das instalações para atender aos objetivos da LEP. As falas remetem à visão compartilhada pelos profissionais da área jurídica: a responsabilidade pelo descumprimento do comando legal não thes é atribuível. Decorre de escolhas políticas, pois depende de investimentos. (MACHADO; SLONIAK, 2015, P. 27)
\end{abstract}

Entende-se, dessa forma, que o trabalho é essencial para a concretização de um sistema penitenciário humanizado, mas que esta pauta não faz parte da agenda da grande parte dos partidos políticos, tendo em vista que a impopularidade de tais medidas acarreta em um ônus do ponto de vista eleitoral e da aprovação popular 
(MACHADO; SLONIAK, 2015, p. 17). A opinião pública, influenciada por discursos midiáticos que clamam pelo retorno de uma cultura meramente punitivista, rechaça o governante que escolhe alocar recursos ou dispender qualquer tipo de esforço em prol da melhoria do sistema penitenciário.

A impopularidade da matéria é tamanha que, em determinados casos, a classe política escolhe permanecer inerte, mesmo quando há recursos financeiros criados especificamente para o investimento no sistema penitenciário. O Fundo Penitenciário Nacional - FUNPEN, criado pela Lei Complementar $n^{\circ} 79$, de 1994, possui, segundo o caput do seu artigo $1^{\circ}$, o objetivo de "proporcionar recursos e meios para financiar e apoiar as atividades e os programas de modernização e aprimoramento do sistema penitenciário nacional”. Entretanto, desde sua criação, o FUNPEN têm seus valores mal aplicados, de modo que foi necessário que se criasse, em 2017, a Lei ${ }^{\circ} 13.500$, proibindo o contingenciamento destes recursos, bastante frequente.

\title{
4.2 A infraestrutura dos estabelecimentos prisionais brasileiros
}

Em relação à questão das más condições estruturais dos presídios brasileiros, Soares et al. (2017, p. 63), mencionam que esta realidade, aliada à superlotação, transforma o cárcere em um ambiente propício à proliferação de todo o tipo de patologias, sejam elas físicas ou psicológicas:

\begin{abstract}
A superlotação da população carcerária juntamente com insalubridade e as más condições estruturais transformam os estabelecimentos prisionais num ambiente ao contágio de doenças. Esses fatores aliados ao sedentarismo, uma vez que não são oferecidas atividades laborais e o uso de drogas, falta de profissionais especializados, dentre outros fatores, fazem com que um preso que adentrou lá numa condição estável, saia da lá acometido de uma doença ou com sua resistência física e saúde comprometida.
\end{abstract}

As más condições estruturais, portanto, levam a várias outras situações problemáticas, principalmente no que diz respeito à garantia da assistência à saúde, prevista na seção III da LEP.

Quando se analisa a situação das mulheres privadas de liberdade nos estabelecimentos prisionais femininos e mistos do país, encontra-se uma situação igualmente preocupante neste sentido. As detentas são submetidas às mesmas condições prisionais que os homens, de modo que suas particularidades físicas, biológicas ou psicológicas não são consideradas (NASCIMENTO, 2013, p. 167). A assistência às mães e gestantes, prevista no art. $14, \S 30$ da LEP e também no art. $83 \S 20^{11}$, se mostra extremamente fragilizada, de modo que estas, na maior parte das vezes, não recebem nem mesmo o acompanhamento médico básico. Neste sentido:

A maioria das detentas grávidas já chega grávida na cadeia. Algumas, já no fim da gestação, nunca passaram por um obstetra, pois eram pobres e desinformadas demais. Como em todo o país só existem 39 unidades de saúde e 288 leitos para gestantes e lactantes privadas de liberdade, na maioria dos presídios e cadeias públicas, elas ficam

\footnotetext{
${ }^{11}$ Art. 14, $3^{\circ}$ "'Será assegurado acompanhamento médico à mulher, principalmente no pré-natal e no pós-parto, extensivo ao recémnascido.”; Art. 83, § 20 “Os estabelecimentos penais destinados a mulheres serão dotados de berçário, onde as condenadas possam cuidar de seus filhos, inclusive amamentá-los, no mínimo, até 6 (seis) meses de idade.”
} 
misturadas com a população carcerária e, quando chega a hora do parto, geralmente alguém leva para o hospital. Já nasceu muita criança dentro do presídio porque a viatura não chegou a tempo, ou porque a polícia se recusou a levar a gestante ao hospital, já que provavelmente não acreditou — ou não se importou — que ela estava com as dores de parto. (QUEIROZ, 2015,p. 42-43)

Construído historicamente por homens e para homens (NASCIMENTO, 2013, p. 183), o Sistema Penitenciário Brasileiro se encontra distante de assegurar a todos os presos a assistência à saúde, prevista no artigo 14 da LEP. As violações aos direitos das mulheres que se sujeitam a este sistema, todavia, são invisibilizadas de maneira ainda mais significativa, tendo em vista que, neste sistema, as mulheres são minorias não somente políticas, mas também numéricas ${ }^{12}$.

\title{
4.3 As afrontas ao princípio da individualização da pena
}

O desrespeito ao princípio da individualização da pena, mais especificamente em seu aspecto executório, também é citado pelos pesquisadores da área de segurança pública como um dos grandes vilões no cenário de violações de direitos característico do sistema penitenciário no Brasil. Os diversos tipos de estabelecimentos penais, previstos nos artigos 82 a 104 da LEP e pensados pelo legislador para atender às diferentes modalidades de penas, acabam por abrigar todo e qualquer tipo de preso, indistintamente. Neste sentido:

\begin{abstract}
No entanto, na prática, essas categorias [de estabelecimentos penais] não funcionam a risca, uma vez que muitos dos presos são deslocados de um estabelecimento para outro, sem haver observância ao artigo $5^{\circ}$ da LEP, que determina que os presos aos ingressarem no sistema penitenciário, sejam classificados, segundo os seus antecedentes e personalidades, para orientar a individualização da execução pena. (SOARES et al. 2017, p. 61)
\end{abstract}

A situação apontada pelos pesquisadores encontra amparo na realidade. Segundo o Ministério da Justiça, em pesquisa realizada por meio do Levantamento Nacional de Informações Penitenciárias INFOPEN, 84\% das unidades prisionais destinadas ao recolhimento de presos provisórios também abrigam presos já condenados. Além disso, $80 \%$ dos estabelecimentos prisionais destinados a abrigar os indivíduos que cumprem pena em regime fechado também abrigam pessoas que cumprem outro tipo de regime. Concluise, assim, que oito em cada dez unidades prisionais brasileiras não funcionam de acordo com a sua atribuição estabelecida em lei, pois abrigam pessoas de mais de um tipo de regime ou natureza da prisão.

Ainda com o objetivo de concretizar o princípio da individualização da pena, presente na Constituição Federativa de 1988 e reafirmado na LEP, o Código Penal, no artigo 59, determina que o juiz deve

\footnotetext{
${ }^{12}$ Ainda que as mulheres sejam minoria no sistema penitenciário brasileiro, se faz importante ressaltar que esta é uma minoria crescente. De acordo com o Levantamento de Informações Penitenciárias - INFOPEN, realizado em junho de 2016, o Brasil possui 42.355 mulheres cumprindo pena de privação de liberdade. Este número representa um aumento de $656 \%$ em relação ao total encontrado no início dos anos 2000, quando a população prisional feminina era composta por menos de seis mil mulheres (BRASIL, 2016, p. 14).
} 
considerar uma série de fatores (culpabilidade, antecedentes, conduta social, personalidade do agente, motivos que levaram à prática do ilícito, circunstâncias e consequências do crime e comportamento da vítima) no momento da aplicação da pena. Neste sentindo, Cristino e Castro (2007) afirmam que, na prática, os magistrados não possuem plena capacidade e assistência profissional para realizar um julgamento acerca da personalidade do agente, de modo que, sob o pretexto de individualizar a pena, nascem decisões judiciais arbitrárias:

De fato, a partir da leitura de sentenças e acórdãos, percebe-se a grande incidência de afirmações genéricas ou restritas a determinações de temperamento e caráter. Não há investigação das bases estruturais da personalidade. O ideal, para evitar a incidência dessas decisões, seria que o juiz não hesitasse em declarar a impossibilidade de valorar a circunstância, reconhecendo a carência de elementos ou sua inaptidão profissional. (CRISTINO; CASTRO, 2007, p. 7)

As autoras entendem, assim, que muitas decisões judiciais que realizam a valoração a respeito da personalidade do agente, com o objetivo de garantir a individualização da pena, geram o efeito contrário, tendo em vista que certos indivíduos acabam por receber um tratamento mais severo, apenas por um suposto estereótipo que, na perspectiva dos magistrados, estes possuem.

A individualização da pena não é prejudicada somente nestes aspectos, mas também no tratamento indistinto dado aos indivíduos que foram presos por diferentes tipos de crimes. Esta realidade decorre, entre outros fatores, da superlotação dos estabelecimentos prisionais e da ausência de capacitação dos agentes penitenciários, mencionada por Soares et al. (2017,p. 61).

Verifica-se, portanto, que o princípio da individualização da pena apresenta problemas em todos os seus horizontes de aplicação, de modo que, nestas condições, se torna impossível efetivar as assistências previstas na LEP, pois estas pressupõem para que sejam fornecidas o conhecimento do indivíduo que seria possibilitado pelo seu atendimento individualizado.

\subsection{As críticas abolicionistas}

Discutindo a questão a partir de um ponto de vista diferente, alguns autores, aparentemente vinculados a um viés abolicionista penal, acreditam que as dificuldades de efetivação da LEP estão relacionadas ao próprio modelo prisional adotado majoritariamente no Brasil e na maior parte do mundo. Defendem, desse modo, que a pena de prisão, da forma como historicamente foi aplicada e também pelo modo como se apresenta atualmente, não é eficaz, servindo somente para o controle social dos indesejáveis. Neste sentido, Ferreira (2011, p. 532) defende que a prisão é desnecessária, pois, por ser um ambiente extremamente degradante, em nada contribui para a reintegração social dos indivíduos:

Conhecendo os fatores sociais, políticos, econômicos, históricos e culturais envolvidos na questão da criminalidade, e, intervindo nas causas do problema, não há por que permanecer com a pena de prisão. Não significa dizer que não se deve ignorar o furto, $o$ 
o roubo, o assassinato, mas permitimos e justificamos as guerras; matar, torturar, espancar torna-se uma ação legítima se feito contra um "criminoso"; permitimos e justificamos a violência institucionalizada; ignoramos as milhares de mortes que ocorrem todos os dias pela fome, pela desnutrição, pela ausência de moradia segura, ou seja, porque essas pessoas não conseguem garantir sua sobrevivência; permitimos e justificamos as infrações às leis trabalhistas e aos direitos sociais. Quem comete esses crimes não vai preso, então, por que prender o pobre em vez de lhe garantir a satisfação de suas necessidades antes que se envolva em práticas consideradas criminosas [sic].

Barcinski, Cúnico e Brasil (2017) também possuem um pensamento crítico ao atual modelo de ressocialização proposto. Desse modo, evidenciam que a concepção de prisão como ambiente capaz de proporcionar a ressocialização é contraditória:

O detento ao ingressar no sistema prisional tem como incumbência a (re)construção da cidadania e da dignidade, sem que o sistema considere as impossibilidades desta construção em um ambiente totalmente privado de liberdade. Há uma contradição entre o processo de reeducar o homem para a liberdade em um ambiente privado de liberdade e estigmatizado socialmente. (BARCINSKI et. al. 2017; p. 1261)

As autoras, portanto, criticam indiretamente o próprio projeto positivado em lei, mostrando-se descrentes em relação à medida de privação total de liberdade. Defendem, desse modo, que a principal solução para os problemas relacionados à criminalidade está na prevenção, que deve acontecer primordialmente por meio da garantia dos direitos fundamentais de toda a população.

\section{CONSIDERAÇÕES FINAIS}

Neste trabalho, os problemas de efetivação dos dispositivos da LEP foram analisados a partir de uma revisão de literatura sobre o tema, que teve como descritores os termos ressocialização e reincidência, tendo sido estes escolhidos em virtude de estarem intimamente ligados à discussão sobre execução penal, como já demonstrado em capítulo apropriado.

Por meio da metodologia adotada, verificou-se que as críticas realizadas pelos pesquisadores da área de segurança pública e execução penal em relação às dificuldades de efetivação dos dispositivos da LEP foram realizadas majoritariamente de modo a apontar fatores gerais que estariam envolvidos no problema. Tal situação não é necessariamente negativa, visto que a maior parte dos artigos consultados na revisão de literatura, bem como os demais textos utilizados como base na realização da presente pesquisa, não possuíam o objetivo principal de apontar falhas específicas neste sentido.

Ainda assim, foi possível perceber algumas realidades mais específicas encontradas como entraves à efetivação da LEP, que foram sistematizadas em quatro tópicos principais, sendo eles: as questões políticas, relacionadas à baixa mobilização dos poderes Executivo e Legislativo no que tange ao aperfeiçoamento do sistema penitenciário brasileiro; as péssimas condições de infraestrutura dos estabelecimentos penais do país, que geram uma série de violações de direitos e impossibilitam a efetivação da assistência à saúde; as afrontas ao princípio da individualização da pena, nos seus mais variados aspectos; e a ineficácia da própria pena de 
prisão, apontada por pesquisadores mais críticos ao atual modelo de justiça retributiva estatal.

Entretanto, resgatando a percepção de que os apontamentos feitos pelos pesquisadores possuem caráter predominantemente generalista, é possível concluir que há uma grande necessidade de que sejam realizadas pesquisas mais específicas em relação a cada faceta deste tema. Ainda que válida, a crítica ao sistema penitenciário, como um todo, pouco acrescenta na resolução das suas problemáticas. Mais eficaz seria que a academia brasileira se debruçasse sobre um - ou mais, desde que de modo específico e com empiria - aspecto da questão por vez, na tentativa de realizar um exame mais profundo a respeito deste, pois este tipo de pesquisa poderia fornecer, de maneira mais adequada, um diagnóstico acerca dos reais problemas relacionados a determinado setor do sistema penitenciário e das possíveis medidas para saná-los.

\section{REFERÊNCIAS BIBLIOGRÁFICAS:}

ADORNO, Sérgio; BORDINI, Eliana. Reincidência e reincidentes penitenciários em São Paulo, 19741985. Revista Brasileira de Ciências Sociais, 1986.

ADORNO, Sérgio. Socialização na delinquência: reincidentes penitenciários em São Paulo. 1991. Cadernos Ceru, 2 (3): 113-147.

BRASIL. Decreto-lei n⿳ 2.848, de 7 de dezembro de 1940. Código Penal. Diário Oficial da República do Brasil. Rio de Janeiro, 7 de dezembro de 1940; $119^{\circ}$ da Independência e 52º da República. Disponível em $<$ http://www.planalto.gov.br/ccivil_03/decreto-lei/Del2848compilado.htm>.Acesso em 08/07/2018.

Lei no 7.210, de 11 de julho de 1984. Institui a Lei de Execução Penal. Disponível em: < http://www.planalto.gov.br/ccivil_03/Leis/17210.htm>.Acesso em 08/07/2018.

Lei no 13.500, de 26 de outubro de 2017. Altera a Lei Complementar no 79, de 7 de janeiro de 1994, para dispor sobre a transferência de recursos financeiros do Fundo Penitenciário Nacional (Funpen), a Lei no 11.473, de 10 de maio de 2007, para permitir a prestação de serviços, em caráter excepcional e voluntário, à Secretaria Nacional de Segurança Pública (Senasp), na qual se inclui a Força Nacional de Segurança Pública (FNSP), e as Leis nos 8.666, de 21 de junho de 1993, e 10.826, de 22 de dezembro de 2003; e revoga a Medida Provisória no 755 , de 19 de dezembro de 2016 . Disponível e m: $<$ http://www.planalto.gov.br/ccivil_03/_Ato2015-2018/2017/Lei/L13500.htm>.Acesso em:22/08/2018.

Lei complementar $n^{0}$ 79, de 07 de janeiro de 1994. Cria o Fundo Penitenciário Nacional -

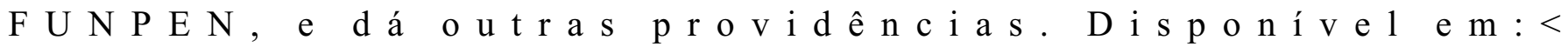
http://www.planalto.gov.br/ccivil_03/LEIS/LCP/Lcp79.htm>.

Constituição (1988). Constituição da República Federativa do Brasil. Brasília, DF: 1988. Disponível em: $<$ http://www.planalto.gov.br/ccivil_03/constituicao/constituicao.htm>. Acesso em 08/07/2018. 
Câmara dos Deputados (2009). CPI Sistema Carcerário. Comissão Parlamentar de Inquérito com a finalidade de investigar a realidade do Sistema Carcerário Brasileiro, com destaque para a superlotação dos presídios, custos sociais e econômicos desses estabelecimentos, a permanência de encarcerados que já cumpriram a pena, a violência dentro das instituições do sistema carcerário, corrupção, crime organizado e suas ramificações nos presídios e buscar soluções para o efetivo cumprimento da Lei de Execução Penal LEP. Disponível em:<http://bd.camara.leg.br/bd/handle/bdcamara/2701>. Acesso em 09/07/2018.

. Instituto de Pesquisa Econômica Aplicada (IPEA). Reincidência criminal no Brasil. Relatório final de atividades da pesquisa sobre reincidência criminal, conforme Acordo de Cooperação Técnica entre o Conselho Nacional de Justiça e o IPEA. 2015. Brasília, Ipea.

. (2014), Departamento Penitenciário Nacional do Ministério da Justiça. Levantamento nacional de informações penitenciárias: INFOPEN junho. Distrito Federal: DEPEN/MJ.

(2016), Departamento Penitenciário Nacional do Ministério da Justiça. Levantamento Nacional de informações penitenciárias: INFOPEN Mulheres, $2^{a}$ edição. Brasília: Ministério da Justiça e Segurança Pública. Departamento Penitenciário Nacional, 2017.

. Supremo Tribunal Federal. Medida Cautelar Na Arguição De Descumprimento De Preceito Fundamental no 347/DF. CUSTODIADO - INTEGRIDADE FÍSICA E MORAL - SISTEMA PENITENCIÁRIO - ARGUIÇÃO DE DESCUMPRIMENTO DE PRECEITO FUNDAMENTAL ADEQUAÇÃO. Cabível é a arguição de descumprimento de preceito fundamental considerada a situação degradante das penitenciárias no Brasil [...]. Relator: Min. Marco Aurélio. Tribunal Pleno. 9 set. 2015. Disponível em: $<$ http://www.stf.jus.br $>$. Acesso em: 20 out. 2018.

BARCINSKI, Mariana; CÚNICO, Sabrina Daiana; BRASIL, Mariana Valentim. Significados da Ressocialização para Agentes Penitenciárias em uma Prisão Feminina: Entre o Cuidado e o Controle. Temas em Psicologia - setembro 2017, Vol.25, nº 3, 1257-1269.

CRISTINO, Fernanda da Rosa; CASTRO, Joelíria Vey de. Análise da personalidade do agente como circunstância judicial de individualização da pena no direito penal contemporâneo. Revista Eletrônica do Curso de Direito da UFSM vol. 1, nº 3, 2007.

CUNHA, Elizangela Lelis da. Ressocialização: o desafio da educação no sistema prisional feminino. Cad. CEDES vol.30 nº.81. Campinas Mai/ago. 2010, p. 157-178.

ESTEVAM, Ionara Dantas; COUTINHO, Maria da Penha de Lima; ARAÚJO, Ludgleydson Fernandes de. Os desafios da prática socioeducativa de previsão de liberdade em adolescentes em conflito com a lei: ressocialização ou exclusão social? Psico, 2009;40(1):p. 64-72

FAJARDO, Sinara. Reincidência ou repescagem? Cadernos do LEPAARQ, 2007, p. 123-142.

FERREIRA, Angelita Rangel. Crime-prisão-liberdade-crime: o círculo perverso da reincidência no 
crime. Serv. Soc. Soc., São Paulo, n. 107, p. 509-534,jul./set. 2011.

FONSECA, Carlos Eduardo Prates; RODRIGUES, Jéssica Marques. Contextos de ressocialização do privado de liberdade no atual sistema prisional brasileiro. Revista Multitexto, 2017, v. 5, n. 01, p. 35-44.

GRECO, Rogério. Curso de Direito Penal: Parte Geral. Vol. I. 19 $19^{\text {a }}$ d. 2017. Rio de Janeiro: Editora Ímpetus, 2017.

LEMGRUBER, Julita. Reincidência e reincidentes penitenciários no sistema penal do Estado do Rio de Janeiro. 1989. Revista da Escola de Serviço Penitenciário do Rio Grande do Sul, 1 (2): 45-76.

MACHADO, Bruno Amaral; SLONIAK, Marcos Aurélio. Disciplina Ou Ressocialização? Racionalidades Punitivas, Trabalho Prisional E Política Penitenciária. Rev. direito GV [online]. 2015, vol.11,n.1, pp.189-222. ISSN 1808-2432.

MARIÑO, Juan Mario Fandino. Análise comparativa dos efeitos da base socioeconômica, dos tipos de crime e das condições de prisão na reincidência criminal. Sociologias [online]. 2002, n.8, pp.220-244. ISSN $1517-4522$

MARQUES JÚNIOR, Gessé. A Lei de Execuções Penais e os limites da interpretação jurídica. Rev. Sociol. Polít., Curitiba, v. 17, n. 33. 2009, p. 145-155.

NASCIMENTO, Lissa Crisnara Silva do. A (in)visibilidade da mulher criminosa e a desigualdade de gênero no espaço da prisão: uma análise da vivência das mulheres em situação de prisão no complexo penal estadual agrícola Drº Mário Negócio em Mossoró/RN. Revistas Transgressões, v. 1 n. 2. 2015.

QUEIROZ, Nana. Presos que menstruam: a brutal vida das mulheres - tratadas como homens - nas prisões brasileiras. 1. Ed. Rio de Janeiro: Record, 2015.

SAPORI, Luis Flávio; SANTOS, Roberta Fernandes; MAAS, Lucas Wan Der. Fatores sociais determinantes da reincidência criminal no Brasil: o caso de Minas Gerais. Revista Brasileira de Ciências Sociais. 2017.

SEQUEIRA, Vania Conselheiro. Uma Vida que não Vale Nada: Prisão e Abandono Político-Social. Psicologia, Ciência e Profissão, 2006, 26 (4), 660-671.

SOARES, Agnaldo Moreira; PEREIRA, Geovana Rodrigues; PEREIRA, Suely Rodrigues; FREITAS, Ronilson Ferreira. Lei de execução penal (LEP) em penitenciária de segurança máxima para ressocialização de apenados: análise de políticas públicas. Revista Multitexto, 2017, v. 5, n. 01, p. 57-66. 